Para enlazar con este artículo / To link to this article:

http://dx.doi.org/10.6035/MonTI.2019.ne4.4

Para citar este artículo / To cite this article:

Manterola Agirrezabalaga, Elizabete. (2019) "Evolución del cine en euskera y su traducción." En: Pérez L. de Heredia, María \& Irene Higes Andino (eds.) 2019. Multilingüismo y representación de las identidades en textos audiovisuales / Multilingualism and representation of identities in audiovisual texts. MonTI Special Issue 4, pp. 113-144.

\title{
EVOLUCIÓN DEL CINE EN EUSKERA Y SU TRADUCCIÓN ${ }^{1}$
}

\author{
Elizabete Manterola Agirrezabalaga \\ elizabete.manterola@ehu.eus \\ Universidad del País Vasco (UPV/EHU)
}

\section{Resumen}

En los últimos años hemos presenciado un auge de las producciones cinematográficas en euskera, por lo que creemos necesario realizar un estudio de su desarrollo. Este artículo pretende, en primer lugar, analizar la terminología y la conceptualización que se esconden detrás de las denominaciones cine vasco y cine en euskera, para después observar la producción y su difusión a lo largo de su historia. Se ha compilado un catálogo de largometrajes que emplean el euskera como lengua vehicular y al analizarlo se deduce que la denominación de película en euskera puede resultar un tanto confusa, dada la idea de monolingüismo que sugiere, en contraposición al multilingüismo presente en numerosas películas. Por último, centraremos nuestra atención en las diferentes modalidades de traducción y la difusión que tienen las películas en euskera tanto dentro como fuera del País Vasco.

\begin{abstract}
"Evolution of cinema in Basque and its translation"

In recent years we have witnessed a boom in cinematographic productions in Basque, so it may be a good time to observe its development. This article aims to analyze the terminology and conceptualization behind the names Basque cinema and cinema in Basque. Filmography in Basque and its distribution will also be observed throughout its history. To this end, a catalogue of feature films that use Basque as their main language has been completed. It can be deduced from it that the name film in Basque can be somewhat confusing, given the idea of monolingualism that it suggests, as opposed
\end{abstract}

1. Este artículo forma parte del trabajo realizado por el grupo de investigación TRALIMA (GIU16/48), financiado por la UPV/EHU. 
to the multilingualism present in numerous films. Finally, we will focus our attention on the different modalities of translation and the diffusion of films in Euskera, both inside and outside the Basque Country.

Palabras clave: Cine vasco. Cine en euskera. Traducción audiovisual. Multilingüismo. Diglosia.

Keywords: Basque cinema. Cinema in Basque language. Audiovisual translation. Multilingualism. Diglossia. 


\section{Introducción}

Esta contribución presenta una visión panorámica sobre la producción cinematográfica en euskera y su traducción. Existen numerosos estudios sobre cine vasco o cine en euskera, pero muy pocos tienen la traducción en su punto de mira. De hecho, las contadas contribuciones sobre la traducción audiovisual se han centrado sobre todo en la producción exterior vertida al euskera (véanse Barambones 2011 y 2012; Barambones, Merino \& Uribarri 2012; Larrinaga 2010; Zabalondo 2010, entre otros). Por ello, hemos querido observar la direccionalidad opuesta y centrarnos en la producción en euskera y su doblaje y subtitulado hacia otras lenguas.

Esta aportación pretende ser un punto de partida para el análisis de la traducción y difusión de la cinematografía vasca, un ámbito que consideramos podría ser muy productivo. Se ofrecen unos resultados preliminares extraídos del catálogo elaborado para este artículo mediante los cuales se pueden observar las tendencias lingüísticas y traductológicas existentes.

En primer lugar, ha sido necesario reflexionar sobre lo que significan los términos cine vasco y cine en euskera, ya que no son nociones estancas ni bien definidas, para definir el objeto de estudio y de catalogación, que hemos limitado a las películas en euskera. El análisis de los productos originales ha sido una tarea fundamental para ello. Los productos analizados son diversos y el multilingüismo está presente en ellos. La hipótesis que plantea esta contribución es que las denominadas películas en euskera son en realidad productos multilingües donde, aparte de una lengua vehicular minoritaria, también existen otras variantes u otras lenguas, con lo que la visión monolingüe que se sugiere mediante su denominación está distorsionada.

El catálogo que hemos diseñado constituye una herramienta muy útil para poder ofrecer un panorama general de la producción en euskera, su traducción y su distribución. Sin embargo, su compilación ha resultado más compleja de lo inicialmente previsto, lo cual se mostrará en el siguiente apartado.

Más adelante se debatirá sobre el multilingüismo y la inclusión de dialectos en los productos originales, y se ilustrará mediante varios ejemplos la tipología existente. La traducción y la difusión de las películas en euskera tanto dentro 
como fuera del País Vasco también será uno de los puntos centrales de esta contribución. El último apartado ofrecerá unas reflexiones finales.

\section{Objeto de estudio}

El adjetivo vasco resulta conflictivo o cuanto menos confuso, ya que puede entenderse de diferentes modos y la compleja conceptualización de la producción cinematográfica vasca resulta en una terminología ambigua. Durante la década de los 70 surgieron los primeros intentos para la creación de una industria cinematográfica vasca y es entonces cuando se comienza a debatir sobre la representación del cine vasco. Aquel debate inicial se ha calmado con los años, aunque hoy por hoy todavía no exista una clara definición de lo que es el cine vasco e incluso sigamos preguntándonos si en realidad existe una cinematografía vasca, teniendo en cuenta lo reducido de la producción y su falta de autonomía. Se podría pensar que una definición estanca no es relevante, aunque en vista de las necesidades de financiación del sector resulta inevitable delimitar qué se va a subvencionar y cuáles son los parámetros para otorgar ayudas².

Cine vasco no es equivalente a cine en euskera, aunque exista una relación interdependiente entre ellos. Cine en euskera es cine vasco, pero el cine vasco no tiene por qué ser en euskera. El cine vasco puede estar ligado a aspectos culturales, territoriales o lingüísticos, mientras que generalmente el denominado cine en euskera se define por la lengua vehicular de una película.

Por otra parte, el cine en euskera perfectamente puede dar cabida a las películas rodadas en otras lenguas que hayan sido dobladas o subtituladas al euskera. Con todo y con ello, la denominación de cine en euskera no parece la más acertada para referirse a la producción original en euskera, aunque a efectos prácticos sea la denominación que se emplea para referirse a las películas rodadas íntegra o parcialmente en en ese idioma.

En vista de que la producción es cada vez más numerosa, nos planteamos como objetivo elaborar un catálogo de obras cinematográficas en euskera, analizar sus características y observar cuál ha sido su difusión en otras lenguas y mediante qué modalidad de traducción audiovisual se han distribuido. El estudio se centra en la producción de largometrajes y deja de lado los cortometrajes y los mediometrajes por la dificultad de acceder a la producción

2. Lo que se establece en las bases de las convocatorias anuales de subvenciones del Gobierno Vasco es bastante amplio, ya que toda persona que haya nacido o que resida en Euskadi puede beneficiarse de tal ayuda, aunque si la producción se realiza en euskera, el solicitante estará exento de cumplir con lo anterior (cf. BOPV 2016). 
global, ya que no existen fuentes disponibles que recojan todos los productos existentes. Por otra parte, hemos recopilado obras de ficción, documentales y películas de animación con la intención de ofrecer una panorámica lo más amplia posible.

Asimismo, hemos adoptado un criterio lingüístico para definir nuestro objeto de estudio. El enfoque y la metodología que se emplean en este estudio se basan en estudios previos sobre la exportación de literatura vasca (cf. Manterola 2014). Teniendo en cuenta que nos enmarcamos en los Estudios de Traducción, se analizan las denominadas películas en euskera, las cuales conforman un discreto sistema desde el punto de vista lingüístico (cf. Mejuto 2011: 51). La clasificación de cada fuente no coincide al 100\%, por ejemplo, Muñoz Manias (2015) clasifica dentro del cine en euskera los productos rodados íntegramente en euskera y analiza los costes de producción y planes de financiación de 11 películas rodadas entre 2005 y 2012. El Euskal Zine Bilera (Festival de Cine Vasco) de Lekeitio, que surge en la década de los 70 para promover la producción audiovisual en euskera ${ }^{3}$ y exhibe únicamente productos rodados en ella, ofrece una perspectiva parecida. Por su parte, el proyecto Ganbara, que tiene como objetivo ofrecer una panorámica histórica de la producción cinematográfica en euskera y servir como archivo digital, ${ }^{4}$ no define claramente lo que clasifica como película en ella, y en su catálogo se pueden encontrar películas monolingües y multilingües, así como películas originales y dobladas. De manera similar, la comparativa de Barambones (2011) sobre películas originales en euskera y películas dobladas y subtituladas al euskera recoge películas monolingües y multilingües como "cine en VO en euskera" (2011: 20). El investigador optó por incluir "aquellas películas que, aunque en su mayor parte estén rodadas en castellano, incluyen diálogos en euskera" así como "aquellas producciones que, aunque estén rodadas en euskera, hacen uso de diálogos en castellano" (Barambones 2011: 1). Por otra parte, en su estudio sobre el papel que desempeña la traducción en el panorama audiovisual vasco actual en diferentes medios y diferentes tipos de productos, Mejuto reconoce que no es raro encontrarse filmes en castellano que introducen diálogos en euskera y viceversa (cf. Mejuto 2011: 51). Por ello, al realizar la catalogación de la producción original en euskera establece dos criterios mínimos: al menos el $50 \%$ del contenido verbal tiene que estar en euskera y al menos el $50 \%$ de los créditos tienen que estar en euskera (cf. Mejuto 2011: 52).

3. Para más información consúltese su página web $<w w w . z i n e b i l e r a . c o m>$.

4. Para información más detallada consúltese su página web < ganbara.eus $>$. 
Este estudio sigue la misma línea para analizar la producción en euskera. Sin embargo, ha resultado difícil fijar un criterio lingüístico claro dada la cada vez más amplia presencia del multilingüismo dentro de las producciones audiovisuales. Cabría recordar lo que mencionan Corrius y Zabalbeascoa (2012: 3): "We could view all texts as being potentially multilingual even though they may have a main language (L1) just as translations may have one main language (L2)". A pesar de ello, creemos que existen tendencias divergentes, algunas hacia el monolingüismo y otras hacia el multilingüismo. El término de «película en euskera» que se utiliza popularmente es un tanto simplista y puede llevar a confusión. Existen, por una parte, películas monolingües, donde la lengua vasca es la única que se oye. Por otra parte, otras películas emplean el euskera como lengua vehicular, pero existe presencia de L $3^{5}$ (Corrius $\&$ Zabalbeascoa 2011), y también hay películas en que tanto el euskera como el castellano son lenguas vehiculares o L1. ${ }^{6} \mathrm{Y}$, por supuesto, existen películas donde el euskera tiene una presencia más testimonial, donde tiene un carácter de L3. Cuando se habla de películas en euskera, normalmente se refiere a las que utilizan el euskera como una de las lenguas vehiculares. Sin embargo, una vez consultadas las fuentes arriba citadas, creemos que no siempre se entiende del mismo modo la noción de lengua vehicular o Ll. El criterio principal para la inclusión de películas en nuestro catálogo es que el euskera sea la Ll de los largometrajes o por lo menos una de las L1.

En esta primera versión del catálogo se han incluido datos desde el 1956, año en que se produjo la primera película con el euskera como Ll, hasta el 2016. En total, se han recopilado 111 películas y los siguientes son los datos correspondientes a cada una: título original y título traducido, director, guionista, productor, año, género, metraje, L1, L3 (en el original), lengua(s) de subtitulación y lengua(s) de doblaje. Cabe señalar que no ha sido fácil recopilar datos fidedignos sobre la L1 y la L3, ni tampoco definir la lengua original en

5. Corrius \& Zabalbeascoa definen así la L3: "L3 notation is to be used to refer to the presence in a text of languages that only account for a small part of the total linguistic output of a text. When two or more languages are so evenly distributed that it becomes difficult to establish a principal language, ore even when a secondary language covers considerably long passages, then it might be more appropriate to consider that in fact we are dealing with a text, or a translation, that has more than one Ll (Lla, Llb, Llc, ...) or maybe even L2, respectively. Likewise, there may be more than one L3 in a given ST or TT (L3a, L3b, L3c, ...)" (2011: 121).

6. Esta es la definición que se hace de L1, entendiéndose esta como lengua vehicular de una película: "Main (or only) language of the source text. [...] The concept of Ll also includes any other language with a significant amount of words" (Zabalbeascoa $\&$ Voellmer 2014: 43). 
el caso de algunas películas de animación. Con todo, creemos que este catálogo puede servir de punto de partida para ahondar en el multilingüismo y la traducción en productos audiovisuales vascos. El anexo I ofrece una visión resumida del catálogo.

\section{El desarrollo del denominado cine en euskera}

Este apartado se centrará en el desarrollo y la evolución de la producción de las películas en euskera y observará la presencia que ha tenido la lengua vasca en pantalla. Aunque lo ideal sería observar el cine vasco en su totalidad y ver qué lugar ocupan en él las películas en euskera ${ }^{7}$, por cuestiones de espacio nos limitaremos a realizar un pequeño repaso a la producción en lengua vasca. Sin embargo, no se puede mantener una visión purista, ya que el euskera tiene protagonismo también en películas que utilizan otras lenguas como Ll.

Aunque el catálogo será la base principal de los datos que aportaremos, también se tendrán en cuenta otras películas que sean referenciales, pero que hayan quedado fuera de nuestra catalogación, ya sea por cuestiones de metraje o por la reducida presencia del euskera en pantalla. Sin embargo, hemos creído oportuno incluir sus referencias aquí para poder ofrecer una visión más completa.

En líneas generales, el cine es una industria dependiente del mercado estadounidense imperado por el uso del inglés. Según Roldán Larreta, "si el cine realizado en castellano sufre ya serios problemas de rentabilidad, películas habladas en euskera tienen un futuro mucho más oscuro" (1996: 164). El reducido número de cineastas capaces de trabajar en euskera y de espectadores potenciales condiciona totalmente las opciones de rentabilidad de dichos productos. Tal y como menciona Mejuto, el mercado vascohablante no es el más tentador: "Just above one million speakers do not constitute the most appealing market for film producers" (2011: 51).

La primera película en que se oye hablar en euskera es Au Pays des Basques $(1930)^{8}$, un documental de 40 minutos dirigido por Jean Faugeres y Maurice Champeaux en el que se muestra la vida cotidiana de los vascos. Posteriormente surgieron varias producciones de carácter documental y también otras de naturaleza propagandística con claros intereses políticos en los que el euskera tuvo

7. Para ahondar en este tema el lector puede consultar, entre otros, Roldán Larreta 1996 y 1999, Martínez 2015 o Gutiérrez 1994.

8. Esta película, al igual que otras que se mencionan en este apartado, no forma parte del catálogo, ya que no cumple con los criterios establecidos para su elaboración. Todas ellas están recogidas en el anexo II. 
un papel más o menos testimonial. Fue el año 1956 cuando se rodó la primera película íntegramente en euskera, dirigida por el general vasco-francés André Madré. Se tituló Gure Sor Lekua y tuvo una duración de 90 minutos, un trabajo dirigido a los vascos de la diáspora. Paradójicamente, la copia recuperada hace poco por Josu Martínez no contiene la pista sonora9 (cf. Martínez 2015). Antes de este descubrimiento se creía que los primeros trabajos en euskera eran cuatro documentales de Gotzon Elorza. ${ }^{10}$

En los últimos años de la dictadura franquista, una nueva generación de artistas y cineastas siguió creando productos de carácter documental. Ama Lur (Nestor Basterretxea y Fernando Larruquert 1968) representa un hito en la historia del cine vasco por su valor etnográfico y artístico (cf. Manias Muñoz 2015: 183). Además, aunque no fuera rodada en euskera, la lengua vasca está de algún modo presente en ella: "In spite of having Spanish as narrative language, Ama Lur ("mother land") is probably the first long film produced in Spain which includes bilingual credits, and speech and songs in Basque" (Mejuto 2011: 53). Otro trabajo interesante es el de Axut (Jose Mari Zabala 1976), una película experimental sin diálogos, pero que cuenta con título y créditos en euskera (cf. Mejuto 2011: 53). A finales de los 70 se produjeron Balantzatxoa (1978), una producción para niños de Juanmi Gutiérrez y la serie de películas documentales Ikuska, supervisada por Antton Ezeiza.

Una vez instaurada la democracia en España y con el Gobierno Vasco al frente de la producción cultural vasca podríamos decir que el cine vasco conoció su edad de oro (cf. Barambones 2011: 6). Durante la década de los 80 se estableció un sistema de subvenciones para producciones de ficción en euskera mediante el que se produjeron 43 largometrajes en el periodo 1981-1991 (cf. Manias Muñoz 2015: 184), de los cuales nuestro catálogo reúne ocho. En aquella época se abogó por reforzar la creación artística y se dieron los primeros pasos para establecer una industria cinematográfica vasca y profesionalizar el sector. Cabe mencionar varios mediometrajes basados en obras literarias, como Ehun metro, de Alfonso Ungría, Zergatik, panpox?, de Xabier Elorriaga o Hamaseigarrenean, aidanez, de Anjel Lertxundi, producidas todas ellas en 1985. Posteriormente vinieron Oraingoz izen gabe (Jose Julian Bakedano 1986) y Kareletik (Anjel Lertxundi 1987), que no tuvieron una recepción demasiado

9. La copia fue descubierta en una casa particular en la que vive la viuda del general Madré. La prensa de la época y los testimonios de primera mano confirman que la cinta se rodó en euskera.

10. Ereagatik Matxitxakora (1959), Aberria/Erria (1961), Elburua: Gernika (1962) y Avignon (1964). 
positiva (cf. Mejuto 2011: 54), no por haber sido rodadas en euskera, "sino más bien por su escasa calidad” (Roldán Larreta 1996: 173). También hubo producciones bilingües en euskera y en castellano, como Ander eta Yul (Ane Díez 1989). Ke arteko egunak (Antton Ezeiza 1989) merece una mención aparte, ya que fue la primera película que entró en la competición oficial del Festival de Cine de San Sebastián. ${ }^{11}$

Parece que la presencia del euskera es cada vez más testimonial: "el compromiso de la productora Irati o de cineastas como Juanba Berasategi, Bakedano, Lertxundi o Ezeiza, queda como un romántico esfuerzo incapaz de todos modos de ocultar una realidad" (Roldán Larreta 1996: 173-174).

Con la llegada de los años 90, el coste de las películas iba en aumento y el Ministerio de Cultura cambió el modelo de promocionar el cine, y obligaba a las películas a recuperar la inversión realizada. En el País Vasco se creó Euskal Media, una institución pública para gestionar las subvenciones cinematográficas. Muestra del cambio drástico que supuso es que en aquella década se rodó una única película íntegramente en euskera (Offeko maitasuna, Koldo Izagirre 1992), además de otras tres películas de animación y otras dos películas bilingües: Urte ilunak (Arantxa Lazcano 1993) y Maité (Eneko Olasagasti y Carlos Zabala 1994), donde el euskera tiene una presencia más testimonial.

Transcurridos algunos años, en 1996 el Gobierno Vasco decidió retomar la vía de las subvenciones que estableció en los 80 y, aparte de ello, se firmaron varios convenios con la Radio Televisión Vasca para la promoción del cine vasco. Además, en los últimos años la inversión realizada por ETB ha ido creciendo de manera sustancial. Después de 12 años sin estrenos, en 2005 llegó Aupa Etxebeste!, dirigida por Asier Altuna y Telmo Esnal, la película en euskera más taquillera hasta Handia (2018). Desde entonces se han estrenado anualmente varias películas con euskera como lengua principal (o al menos como una de las lenguas principales). Aunque no se trate de una producción abundante, sí parece tener cierta continuidad. Continuidad que se ha visto afectada por la crisis económica de los últimos años y la reducción de las subvenciones públicas. ${ }^{12}$

El siguiente gráfico muestra la evolución de la producción anual. ${ }^{13}$ Como se puede observar, se han estrenado pocos largometrajes hasta el nuevo milenio.

11. La película tuvo una recepción controvertida debido a la temática que trataba. Para más información, consúltese El cine del País Vasco; de Ama Lur (1968) a Airbag (1997) (1999), de Roldán Larreta.

12. Según Manias Muñoz, entre 2010 y 2013 el presupuesto se redujo un 61 \% (2013: 95).

13. En el anexo I, titulado "Catálogo", se puede consultar el listado completo de títulos. 
A partir del año 2002 vemos que la producción va aumentando, aunque no de manera continuada, y existe una subida considerable a partir de 2010.

Figura 1. Cronología de la producción de cine en euskera entre 1956 y 2016

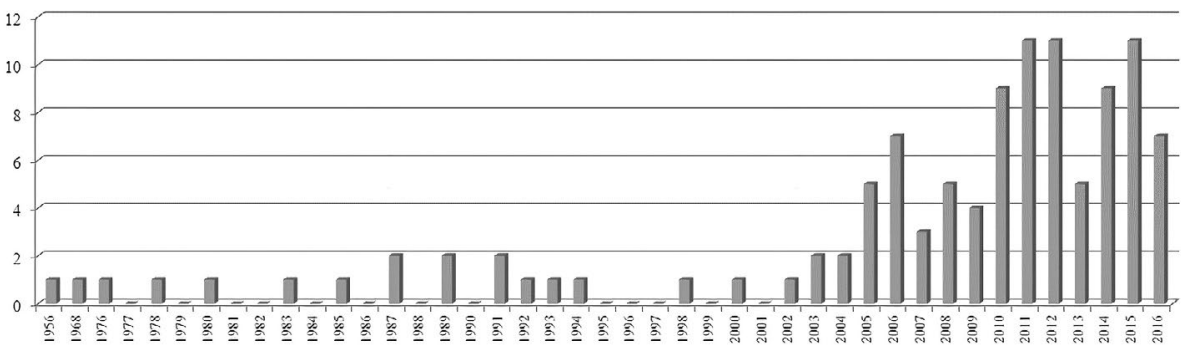

Por lo que se refiere al género, hemos contabilizado un total de 34 películas de animación, 35 documentales, 2 largometrajes experimentales y 40 obras de ficción (27 películas dramáticas, 6 comedias, 3 películas de aventuras para niños y jóvenes, 3 thrillers y 1 musical).

Figura 2. Largometrajes en euskera por géneros

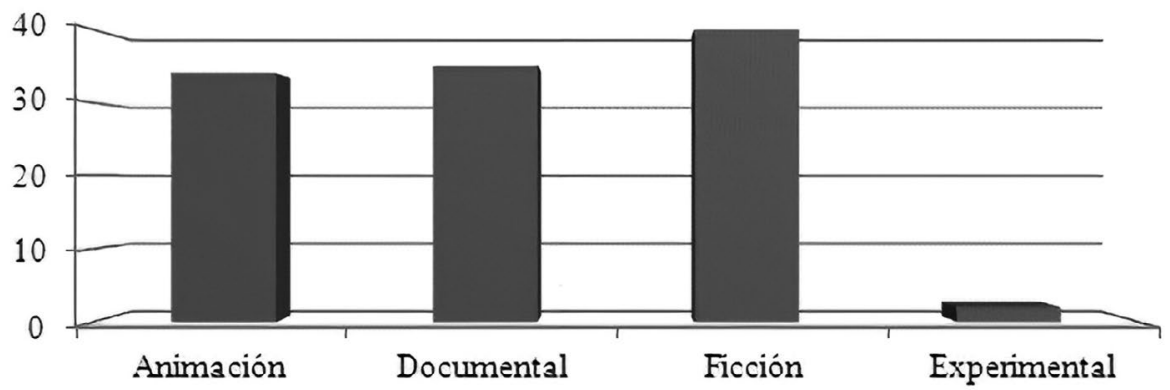

El siguiente gráfico puede resultar ilustrador para observar los géneros de manera cronológica. En él hemos distribuido la producción por géneros y décadas, desde 1970 hasta la actualidad. 
Figura 3. Distribución cronológica de los géneros

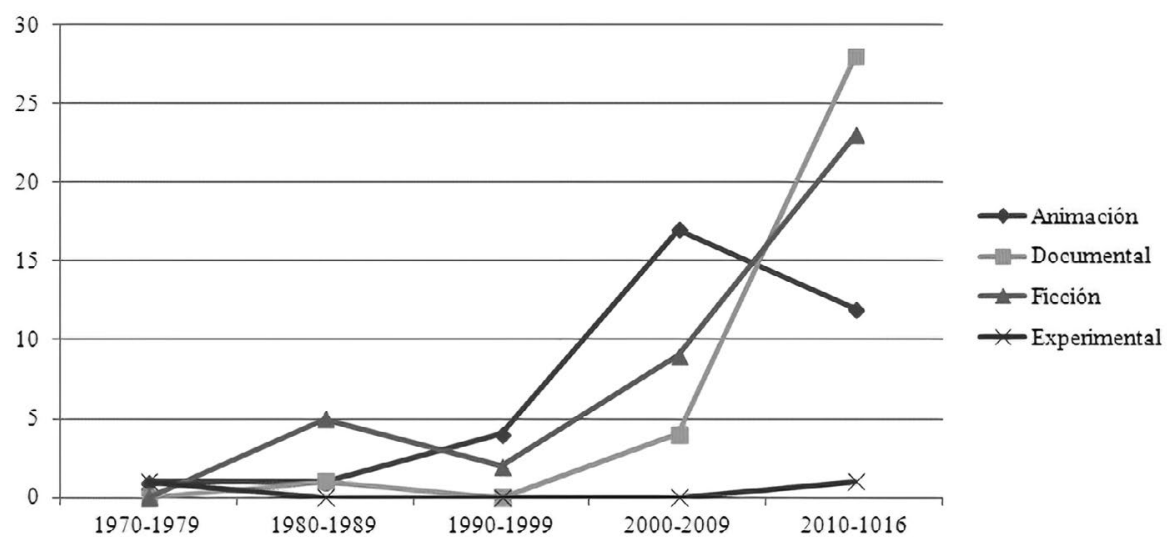

Se observa que en los años 80 la ficción tuvo una primera etapa productiva, más aún si tuviéramos en cuenta los mediometrajes de ficción que se han quedado fuera de catálogo, y, posteriormente, en los 90, descendió. Sin duda, a partir del nuevo milenio hay una subida notable bastante continuada. En el caso de los documentales, el gráfico muestra que, hasta la década del 2000, la producción es casi nula, pero desde entonces ha tenido un crecimiento exponencial, sobre todo en los últimos años. Por otra parte, cabe destacar que, desde los 80, el sector de la animación ha venido desarrollándose poco a poco y tuvo una subida considerable en la década del 2000, aunque en los últimos años parece que no ha seguido aumentando. Téngase en cuenta que el último periodo que aparece en el gráfico es algo más corto que los demás, por lo que no se puede hablar de un descenso.

Más allá de los datos cuantitativos, podría decirse que los productos son cada vez más diversos en cuanto a estilo, género o registro lingüístico, y su calidad es más que aceptable. Por contra, la fragilidad de la industria se hace notar en la dependencia de las subvenciones públicas, tal y como ocurre en otros lugares, por lo que una crisis económica como la que hemos sufrido desde 2008 tiene consecuencias directas en ella y la condiciona completamente. Por otra parte, la respuesta por parte del público no es la que cabría esperar (cf. Manias Muñoz 2013: 87): la gente no acude a las salas de cine y las películas permanecen en pantalla durante un periodo temporal limitado. 


\section{El multilingüismo y la presencia de diferentes variantes en las versiones originales}

Creemos conveniente analizar la versión original de las películas de nuestro catálogo antes de observar sus correspondientes versiones traducidas. Para ello, observaremos primero su carácter (monolingüe o multilingüe) para después analizar el tipo de lenguaje que se utiliza en ellas y ver si las variantes empleadas necesitan algún tratamiento concreto para su recepción por parte de los espectadores. La utilización de los dialectos o el estándar pueden aportar más o menos credibilidad a una película y acercar la historia a su entorno más cercano, aunque es difícil hacer generalizaciones, ya que dependerá de las estrategias utilizadas en cada película y del resultado obtenido.

El multilingüismo de los productos audiovisuales es visible incluso antes de llegar el producto a pantalla. Hay directores de cine no vascohablantes, o que no tienen un dominio semejante de ambas lenguas, que han rodado películas en euskera. En dichos casos, se entremezclan las dos lenguas en los procesos de escritura del guion, rodaje o producción. En el caso de Bi anai (Imanol Rayo 2011), por ejemplo, varios borradores del guion se escribieron en castellano antes de la versión definitiva en euskera que se utilizó en el rodaje. Se trata de un guion basado en la novela del mismo título de Bernardo Atxaga, lo cual nos indica que el texto de algún modo ha sido traducido primero del euskera al castellano y del castellano al euskera para el rodaje. En el caso de Lasa eta Zabala (2014), por otra parte, su director, Pablo Malo, no es vascohablante, pero se puso al frente de un proyecto bilingüe. Según el guionista y creador del proyecto, Joanes Urkixo, seleccionar la lengua de rodaje fue una de las principales decisiones que tuvo que tomar:

La primera decisión de urgencia fue que la película fuera bilingüe. Parecía lo más sensato que los personajes hablaran en su forma natural: refugiados vascos, familiares y población local en euskera, en castellano los guardias civiles así como todo el sumario y el juicio (Urkixo 2014).

Sin embargo, la decisión inicial se tuvo que adecuar a otro tipo de exigencias igualmente necesarias para sacar adelante el proyecto:

Para optar a las ayudas a la producción en euskera (algo mayores que en el caso del castellano) al menos un $50 \%$ de los diálogos tendrían que ser en dicha lengua. Sin duda esto limitaba un tanto las opciones narrativas y me cargaba con el trabajo añadido de las traducciones, pues Pablo Malo no habla euskera (Urkixo 2014).

Como se aprecia en estas palabras, la financiación es clave a la hora de diseñar el empleo de la lengua vehicular. 
Existe otro caso curioso en lo respectivo a la elección lingüística. En 1989, Antton Ezeiza estrenó en el Festival de Cine de San Sebastián su primer largometraje dentro del cine vasco, titulado Ke arteko egunak. El rodaje se realizó casi en su totalidad en euskera; eso sí, como el protagonista, el actor mexicano Pedro Armendáriz Jr., no hablaba euskera, tuvo que ser doblado para la versión original (cf. Goñi 2014). Aunque el producto final se visualice en pantalla íntegra o parcialmente en euskera, en realidad el proceso no es monolingüe y puede haber necesidades de traducción en diferentes fases. Es decir, existe una traducción intratextual antes de llegar el producto a la pantalla.

En lo referente a los productos de animación, en la mayoría de los casos, ya desde la fase de creación se proyecta que tendrán más de una versión, sea en euskera y castellano u otras lenguas, como el catalán o el inglés. Además, en los últimos años se han abierto camino primero coproducciones entre empresas vascas y españolas y, más tarde, coproducciones internacionales ${ }^{14}$ en las cuales existe una versión en euskera, otra en castellano, otra en inglés y puede que en más lenguas. Cuando existe colaboración internacional a nivel de producción, es necesario que el guion esté en inglés y que después se vaya traduciendo a las demás lenguas. ${ }^{15}$

A continuación, nos centraremos en la(s) lengua(s) vehicular(es) de las películas vascas y mostraremos varios ejemplos de películas en que se emplea más de una lengua en pantalla.

Tal y como se ha señalado arriba, bajo el paraguas de cine en euskera se clasifican películas filmadas en una única lengua, como podría ser el caso de Amama (Asier Altuna 2015), o Loreak (Jon Garaño y Jose Mari Goenaga 2014). Cierto es que en estas películas se introduce alguna expresión o algún cartel en pantalla de manera aislada en castellano, muestra de la convivencia de ambas lenguas en territorio vasco. En ocasiones se trata de frases o de palabras ya acuñadas en euskera que no suponen problemas de comprensión. Podríamos decir que la presencia de L3 es casi inexistente.

Por otra parte, en muchas otras películas, cuya lengua principal es el euskera, aparece algún que otro personaje que habla en otra lengua, por lo que

14. Consúltese el artículo "El camino de la coproducción en el largometraje de animación vasco" (2016) de Maitane Junguitu para ahondar en este tema.

15. En el caso de Pixi Post y los genios de Navidad (Gorka Sesma 2016), su productor Juanjo Elordi menciona que la historia fue escrita primero en euskera y que fue traducida al inglés para la búsqueda de socios para la coproducción internacional (cf. Aramendi 2014). No es el único caso de coproducción. Su anterior película Yoko eta lagunak (Juanjo Elordi 2015) fue una coproducción entre empresas de Rusia, Cataluña, País Vasco y América (cf. Aramendi 2014). 
la L3 tiene una presencia más amplia. Lo más común es que esa segunda lengua sea el castellano, aunque también aparecen otras lenguas, como el gallego o el italiano en Kareletik, o el alemán y el inglés en Amaren eskuak (Mireia Gabilondo 2013). Esta tendencia a utilizar varias L3 parece ser recurrente.

Tampoco es de extrañar que exista presencia de diferentes L3 en los documentales. Nömadak TX (Raúl de la Fuente, Harkaitz Martínez de San Vicente, Igor Otxoa y Pablo Iraburu 2006) trata sobre el instrumento musical de la txalaparta. Fue rodada en diferentes localizaciones (Mongolia, Laponia, India, etc.) y recoge testimonios de personas de cada uno de estos lugares. El documental Amerikanuak (Gorka Bilbao y Nacho Reig 2010) trata sobre la emigración vasca a Estados Unidos, por lo que se emplean el euskera y el inglés como lenguas vehiculares. Jai Alai Blues (Gorka Bilbao 2015) se centra en la cesta punta, en su presencia en las Américas (Estados Unidos, Cuba, México), y recoge numerosos testimonios en euskera, castellano e inglés. Son solo unos ejemplos de un amplio número de documentales con testimonios en más de una lengua. Estas cintas incorporan subtítulos en euskera para las L3 en sus copias originales.

Asimismo, otras películas cuentan con dos lenguas principales. Es el caso de Arriya (Alberto Gorritiberea 2011) o Lasa eta Zabala. Cabría analizar ambos casos detalladamente para identificar la función atribuida a cada lengua y el porqué de utilizarlas. De hecho, ya hemos mencionado anteriormente que para el guionista de Lasa eta Zabala lo más sensato era que los personajes hablaran en su forma natural (cf. Urkixo 2014). Sin embargo, también existen otras películas y otros productos audiovisuales de ficción donde se prima la utilización del euskera como única Ll y donde personajes que en un plano real hablan en castellano (policías o personas foráneas, por ejemplo) aparecen de una manera natural empleando el euskera. Se trata de dos corrientes contrapuestas que coexisten en la filmografía vasca actual y que no buscan un mismo efecto mediante sus productos: por un lado, algunos buscan ficcionalizar la realidad sociolingüística vasca para crear productos en euskera e impulsar la creación cultural en dicha lengua, conscientes de que el uso real del euskera es bastante menor de lo que se ve en pantalla; por otro, se quiere reflejar en pantalla una realidad diglósica en la que el empleo de ambas lenguas intenta reflejar diálogos directos y reales que se dan en el día a día, aunque la presencia en pantalla de ambas lenguas no se corresponda al $100 \%$ con la realidad.

Otras películas cuya trama principal sucede en castellano o en alguna otra lengua insertan el euskera de manera bastante testimonial. ${ }^{16}$ Por ejemplo, en

16. Los casos en que el euskera no representa una de las L1 han quedado fuera de nuestra catalogación y consideramos que también quedan fuera de lo que se denomina cine en 
una escena de la película Obaba (Montxo Armendáriz 2005), varios personajes cantan un villancico en euskera. Sería interesante analizar la intención que tenía el director al introducir dicho villancico: si quería marcar la geografía y la cultura en que se sitúa la historia o sugerir que realmente los personajes son originalmente vascohablantes. Por lo que se refiere a la aparición del euskera como L3, también puede realizarse un uso estereotipado de la lengua, como sería el caso de Ocho apellidos vascos (Emilio Martínez-Lázaro 2014). Tanto el marcado acento de varios personajes al hablar en castellano como la introducción de expresiones en euskera ayudan a exagerar aún más los rasgos identitarios totalmente estereotipados de dichos personajes.

Por otra parte, es interesante observar el tratamiento que se hace de los diferentes dialectos vascos. Aunque la televisión vasca y la producción cinematográfica en general hayan abogado por primar la utilización del euskera estándar, ${ }^{17}$ se pueden encontrar productos en que se introducen dialectos. La dramatización en un euskera que se asemeje a la realidad (mediante su representación en un dialecto) puede contribuir a la verosimilitud de una obra. En la película Oraingoz izen gabe ${ }^{18}$, "los dos protagonistas hablan en dialecto vizcaíno, tal como ocurre en la realidad, con lo que el texto audiovisual resulta coherente y gana en credibilidad" (Barambones 2011: 10). Asimismo, un producto audiovisual resultará más cercano o más lejano al espectador dependiendo del dialecto seleccionado. La comedia Aupa Etxebeste!, por ejemplo, utiliza principalmente el dialecto guipuzcoano, variante más cercana al estándar que es también la variante de un amplio número de espectadores de productos audiovisuales en euskera. Además, dicho dialecto está muy presente en la televisión vasca y resulta muy familiar a hablantes de otros dialectos, por lo que su utilización en productos audiovisuales no resulta problemática si atendemos a cuestiones de comprensión y cercanía. Además, al tratarse de una comedia, el empleo del dialecto responde a un deseo de crear humor de un modo que resulte natural al espectador, ya que algunos creen que el estándar

euskera, pero consideramos pertinente mencionar estos casos aquí para aportar una perspectiva más completa.

17. "Debido a una política extremadamente conservadora y proteccionista, existe un excesivo respeto al estándar que impide que otros registros más coloquiales se puedan escuchar en los medios de comunicación y especialmente en la televisión pública vasca ETB-1" (Barambones 2011: 4). Cabe señalar que Barambones analiza no solo la producción original, sino también el doblaje hacia el euskera, donde se ha primado el estándar.

18. La versión primera del guion es obra de Bernardo Atxaga en euskera estándar y posteriormente se adaptó al dialecto vizcaíno (Barambones 2011: 10). 
no representa del mismo modo la oralidad o no resulta tan creíble para la vis cómica $^{19}$.

Por su parte, Xora (Peio Cachenaut 2012) es la primera y de momento única película rodada íntegramente en dialecto suletino, el cual se habla en la provincia de la Soule, en el País Vasco francés. Este dialecto se aleja bastante del estándar y su difusión es más limitada, por lo que resulta difícil de comprender para un público mayoritario del País Vasco español. Por ello, con la intención de garantizar la comprensión de la trama y obtener una mayor difusión entre el público general se añadieron subtítulos en euskera estándar.

Por último, un dialecto puede tener una presencia limitada dentro de un producto audiovisual, es decir, puede constituir una L3. En el documental Xalbador, izena eta izana (Eneko Dorronsoro 2014), que trata sobre la vida del bertsolari ${ }^{20}$ Fernando Aire, por ejemplo, se entrevista a varias personas que hablan en dialecto labortano y suletino a las que no es tan fácil entender. El equipo técnico tuvo que decidir subtitular o no ciertas partes. Según la montadora de la película, los profesionales no cuentan con ningún protocolo que marque unas pautas para saber cuándo hay que subtitular o no dichos fragmentos. Además, hay que decidir si los dialectos se subtitulan en dialecto o en estándar: si se introducen subtítulos en estándar, resultará muy raro y en ocasiones molesto escuchar hablar en dialecto y leer algo diferente por escrito; por otra parte, como los dialectos no tienen una forma escrita normativizada, al espectador le resultará difícil leer los subtítulos en un sistema escrito al que no está acostumbrado. Hoy por hoy, todas estas decisiones quedan en manos de los profesionales técnicos, que pueden mostrar más o menos sensibilidad ante cuestiones lingüísticas, por lo que la calidad lingüística del producto final podrá variar de una película a otra dependiendo de la sensibilidad lingüística de cineastas y técnicos.

\section{Traducción y difusión del cine en euskera}

El nivel de conocimiento y uso del euskera no es homogéneo debido a la división administrativa en tres territorios diferentes y a las políticas lingüísticas

19. El debate sobre el empleo del estándar o dialectos en la producción audiovisual sigue hoy por hoy abierto, tanto en relación al cine como a la televisión. El modelo que se ha impulsado desde ETB prima el estándar como herramienta de comprensión para todos los vascohablantes, pero al mismo tiempo se ofrecen en la cadena vasca programas de humor que emplean un dialecto como gancho para los espectadores.

20. Los bertsolaris son improvisadores populares de versos. Improvisan sus cantos atendiendo a una melodía concreta, siguiendo unas reglas de rima y métrica. Se trata de una actividad que hoy por hoy sigue muy presente en la cultura vasca. 
que están en vigor en cada uno de ellos. Cabe señalar que más de la mitad de la población es monolingüe en francés o español y no tiene conocimientos de euskera (solo el 26,6 \% es vascohablante).

La realidad sociolingüística influye directamente en la producción y el consumo de productos audiovisuales en materia lingüística. Lo habitual al distribuir películas de animación es emitirlas en euskera. Las películas de ficción, por su parte, se estrenan en salas comerciales en versión original subtitulada en castellano en Hegoalde ${ }^{21}$ y en francés en Iparralde ${ }^{22}$ debido al alto porcentaje de no-vascohablantes. Esta política de incluir subtítulos interlingüísticos favorece, por una parte, una mayor accesibilidad en salas comerciales a personas no vascófonas, pero, por otra, puede resultar un inconveniente para los que sí lo son: "No debe olvidarse el hecho de que los vascohablantes también saben castellano, por lo que los subtítulos en castellano más que ayudarles a seguir los programas ${ }^{23}$ lo único que consiguen es distanciarles y llevarles a hacer comparaciones entre lo que escuchan y leen" (Barambones 2011: 13). Aparte de la versión subtitulada, en ocasiones también se distribuye la copia doblada. Un ejemplo bastante reciente es el de la película Amama, la cual se emitió simultáneamente en versión original subtitulada y en versión doblada. Esta doble oferta puede ser beneficiosa para los espectadores, que podrán optar por la que más les convenga, aunque puede que no siempre sean conscientes de la existencia de dos copias diferentes, por lo que alguien puede ir al cine pensando que va a ver la película en versión original y acabe en una sesión doblada. ${ }^{24}$ Por lo que se refiere a las películas documentales, dependiendo de la inversión destinada a la producción y a la difusión se estrenan en salas comerciales o en circuitos más pequeños o alternativos. Los criterios lingüísticos suelen corresponderse con los de las películas de ficción, aunque en los circuitos más pequeños de zonas muy vascófonas puede haber casos en que

21. Denominación en euskera para referirse al País Vasco español, que alberga las provincias de Bizkaia, Araba, Gipuzkoa y Navarra.

22. Denominación que hace referencia al País Vasco francés, compuesto por las provincias de Labort, Baja Navarra y Sola.

23. Aunque Barambones se refiere a los programas doblados al euskera que incorporaban subtítulos en castellano en los inicios de la televisión vasca (ETB), una forma de emisión poco habitual, sus palabras sirven igualmente para referirse a lo que ocurre hoy en día en salas comerciales.

24. Las preferencias de los telespectadores por ver la copia doblada o la copia subtitulada pueden ser diferentes dependiendo de su dominio lingüístico o por la costumbre de ver una u otra modalidad. A principios de 2017 TVE emitió la película Loreak en su versión doblada al castellano dentro del programa Versión española. Posteriormente, en las redes sociales y en diferentes medios se debatió si sería más conveniente o no que hubiera ofrecido la versión subtitulada. 
se distribuya una copia monolingüe en euskera, sin necesidad de subtítulos. Por otra parte, en raras ocasiones se llega a doblar las películas documentales, por lo que generalmente se distribuye la copia subtitulada.

Por lo tanto, podríamos concluir que las películas de animación son las únicas que se emiten sin traducción en el País Vasco, ya que tanto las películas de ficción como las documentales suelen incorporar la versión traducida bien al francés, bien al español, a través de los subtítulos o el doblaje. Creemos que es importante señalar que, al ir a ver la versión original subtitulada de una película en euskera, los espectadores en pocas ocasiones tienen acceso en sala a la copia original, copia que a priori se crea para el público vascohablante; en su lugar, lo que reciben es el producto junto con su traducción, sea a través de los subtítulos o del doblaje. El objetivo de que las películas las pueda comprender la mayoría del público hace que los vascohablantes no tengan derecho a recibir en salas comerciales el producto original que en un principio se produce para que sea consumido sin su correspondiente traducción. El único modo de acceder a la copia sin traducción será por medio de plataformas digitales, el DVD o la televisión, es decir, se limitará a un entorno privado.

Por lo que se refiere a la emisión de largometrajes en televisión, en la gran mayoría de los casos, las denominadas películas en euskera se emiten en el primer canal de ETB, que ofrece toda la programación en lengua vasca, tanto las películas íntegramente en euskera como las que lo están de manera parcial. Sin embargo, existen excepciones, como la de Barrura begiratzeko leihoak (2012), documental que habla sobre cinco presos y su vida en la cárcel. Su estreno fue muy controvertido por la temática que trata (presos de ETA). Aunque se esperaba que se exhibiera en el Festival de Cine de San Sebastián, al final no fue aceptado dentro del ciclo Zinemira, dedicado al cine vasco. ${ }^{25} \mathrm{En}$ su estreno televisivo (octubre de 2015), que se realizó en la segunda cadena de la televisión vasca (ETB2), canal que emite todo su contenido en español, se emitió la versión en castellano en contra de la tónica general de la cadena de estrenar las películas en euskera en la primera cadena (ETB1). Las expectativas políticas que se crearon en torno a esta película influyeron en dicha decisión.

Por otra parte, al analizar la difusión de películas en euskera hay que tener en cuenta lo que supone que la copia original incorpore ya una traducción (sea interlingüística o intralingüística). A fin de llegar a un público lo más amplio posible, normalmente se prioriza la emisión con los correspondientes

25. El documental estuvo marcado por polémicas políticas. El delegado del Gobierno de España en la Comunidad Autónoma Vasca remitió a la Fiscalía de la Audiencia Nacional un escrito en el que pedía estudiar si hubo delito en la proyección del documental en el Teatro Victoria Eugenia. 
subtítulos en lengua mayoritaria, por lo que la copia original con subtítulos en euskera tendrá de por sí una difusión limitada y no coincidirá con la práctica habitual de emitir el producto junto con la traducción interlingüística. En el caso de las dos películas mencionadas en la sección anterior (Xora y Xalbador, izena eta izana), ambas con subtítulos intralingüísticos, su emisión en salas comerciales u otros circuitos más pequeños puede acarrear ciertas dificultades, ya que se tendrá que decidir si se garantizará la comprensión en euskera estándar o se tratará de llegar a un público más amplio, lo cual implica que los vascohablantes tengan que leer los subtítulos en la lengua hegemónica.

En ocasiones la inclusión de más de una lengua acarrea dificultades, tanto al diseñar la copia original como al traducirla a otras lenguas. En el documental Barrura begiratzeko leihoak que acabamos de mencionar, la lengua vehicular del narrador es el euskera, y la mayoría de conversaciones también discurren en dicha lengua, aunque el castellano está muy presente en ciertos fragmentos y también hay escenas en francés; ambos casos aparecen subtitulados en euskera. El documental también contiene varios grafismos en euskera, es decir, texto escrito en pantalla que se necesita comprender para seguir el hilo argumental. Paralelamente a la copia original, también se crearon las versiones subtituladas en castellano, francés e inglés para impulsar su difusión en otros lugares. El problema surge al tener que traducir también por escrito los grafismos, ya que este tipo de información suele aportarse mediante los subtítulos. Como los grafismos pueden aparecer junto con la voz en off, los subtítulos no pueden recoger ambas informaciones. Lo adecuado hubiera sido pensar en la traducción antes del rodaje, es decir, al preparar la copia del guion para rodaje, en lugar de actuar posteriormente sobre la copia original y evitar que el montaje pueda resultar muy complicado. Cualquier cineasta que trabaje con productos multilingües, y en especial aquellos que trabajan en entornos bilingües o diglósicos, debería ser consciente de las necesidades de traducción que tendrán sus productos, por lo que sería oportuno recapacitar sobre el tratamiento lingüístico de sus obras ya desde la fase del guion.

Para terminar con la difusión en el País Vasco, mencionaremos brevemente las dificultades que sufren las películas producidas en Hegoalde en su distribución en el País Vasco francés. La producción cultural en euskera es muy escasa en el País Vasco francés debido a la falta de oficialidad del euskera en dicho territorio, por lo que el consumo de cine en euskera se reduce casi exclusivamente a las películas producidas en el País Vasco español. El estado francés aplica un cupo al cine extranjero con el objetivo de defender su cine nacional y como el consumo exterior principal lo ocupan las películas norteamericanas, no hay espacio para las demás (cf. Martínez et al 2015: 727). 
Es difícil marcar límites entre lo que es el mercado propio y el exterior en el caso de las traducciones al español, ya que, como bien hemos observado, el español está muy presente en la cultura de origen. Por lo que se refiere a las diferentes modalidades de traducción, las versiones subtitulada y doblada al español sirven para su difusión tanto en el País Vasco como en el resto de España y países latinoamericanos. Tal y como hemos indicado antes, las películas de ficción cuentan con una copia doblada aparte de la subtitulada, ya que el público español está más acostumbrado a las películas dobladas que a las subtituladas.

Las traducciones hacia otras lenguas se realizan sobre todo para subtitulado: las copias con subtítulos en francés se distribuyen sobre todo en el País Vasco francés, pero también en el resto de Francia, mientras que la copia en inglés suele ser la versión internacional que llega a diferentes países. Es difícil aportar información detallada sobre su difusión, pero se podría decir que en general tienen una recepción muy modesta, aunque cabe mencionar la excepción de Loreak, que consiguió una nominación en los Óscar, por lo que tuvo una presencia notoria en el ámbito internacional.

En el caso de la animación, por último, en general se distribuyen las copias dobladas, tal y como hemos indicado antes, práctica habitual en el caso de productos para el público infantil. Podemos encontrar copias dobladas en otras lenguas, como el inglés, sobre todo si se trata de proyectos internacionales. ${ }^{26}$

El deseo de llegar a un público más amplio está ligado no solo al anhelo de un mayor reconocimiento, sino también al aspecto económico. Según Telmo Esnal y Asier Altuna, uno de los retos de las películas en euskera es que salgan de nuestras fronteras, ya que el País Vasco es demasiado pequeño y, si las películas solamente se comercializan en él, es difícil obtener beneficios (cf. Aramendi 2014). Por lo tanto, la distribución exterior está estrechamente ligada a la rentabilidad de las películas.

Para finalizar, podríamos decir que, al tratarse de una cinematografía reducida y marginal dentro del mercado nacional e internacional, es imposible

26. De hecho, en el caso de películas de animación coproducidas internacionalmente, no es fácil definir claramente la originalidad de una obra. Todo apunta a que la versión original de la película Pixi Post eta opari emaileak (Gorka Sesma 2016) es la versión en euskera, según el IMBD (http://www.imdb.com/title/tt6287174/?ref_=ttfc_fc_tt) o la propia página de la productora (http://www.pixipost.net/index.php/eu/). Sin embargo, la versión del guion sobre la que se basó la animación labial fue la inglesa y la relación entre las productoras también se desarrolló en inglés. Paradójicamente, la película ha sido estrenada antes en euskera y en castellano. 
competir con producciones más comerciales, por lo que las películas en euskera se estrenan en circuitos modestos.

\section{Reflexiones finales}

Esta contribución sobre el cine en euskera ha mostrado que el multilingüismo y su traducción constituyen un amplio campo de estudio que hasta la fecha no se ha analizado a fondo.

Desde el punto de vista sistémico, existen cuestiones identitarias que no están del todo claras bajo las denominaciones de cine vasco y cine en euskera, y en ocasiones se confunden. Aunque no sabemos hasta qué punto es necesario contar con definiciones estancas o marcar diferencias, tratándose de un sistema que depende en un gran porcentaje de financiación pública, las instancias responsables deben delimitar lo que es financiable y lo que no, lo que es cine vasco y lo que no, lo que es cine en euskera y lo que no, en función de los parámetros utilizados para otorgar las ayudas.

Por lo que se refiere a cuestiones terminológicas y conceptuales, consideramos que la denominación popular de cine en euskera no es del todo acertada para una cinematografía que no se limita al euskera como lengua única de sus productos, y creemos que, de algún modo, bajo esa denominación se pretende esconder su carácter diglósico. Teniendo en cuenta los ejemplos mencionados a través del artículo, nos podemos preguntar a qué nos referimos al utilizar la noción de cine en euskera: ¿productos rodados en euskera? ¿Películas multilingües en que el euskera sea una de las lenguas vehiculares? ¿Se tiene en cuenta lo que se escucha en pantalla o también entran en juego la dirección, el guion o el mismo rodaje? Cierto es que una película necesita de muchos y muy variados profesionales en su desarrollo, y es difícil encontrar a tantos profesionales que dominen la lengua vasca. Pero, la denominación de cine en euskera sugiere una idea bastante distorsionada de lo que sucede en el transcurso de una producción cinematográfica.

Los datos recogidos demuestran que la producción cinematográfica en euskera ha sido muy reducida y discontinua, aunque en la actualidad vaya en aumento. Tal y como apunta Manias Muñoz, cada vez hay más profesionales, pero hoy por hoy todavía no se puede hablar de estabilidad (cf. Manias Muñoz 2015: 447). El aumento de la producción responde a las medidas y a los convenios adoptados por el Gobierno Vasco y la televisión vasca para apoyar el cine en euskera (cf. Manias Muñoz 2015: 447).

Lo que denominamos cine en euskera nos ofrece una casuística muy amplia para analizar la representación del bilingüismo de la sociedad vasca, así como la presencia de otras lenguas en nuestro entorno. La representación de las 
diferentes lenguas y dialectos empleados (en forma de L1 o L3) en cada caso nos puede aportar información sobre cómo se configura la identidad y el multilingüismo en la cultura vasca. Por una parte, sería interesante analizar el significado que adoptan las diferentes L3 en las películas en euskera, tanto cuando se trata de una lengua natural o un dialecto. También sería interesante analizar la tendencia opuesta, es decir, qué aporta introducir el euskera en calidad de L3 en películas en español. Por otra parte, existen tendencias contrapuestas en la utilización de la(s) lengua(s) vehicular(es): algunas películas emplean el euskera como única L1, mientras que otras intentan reflejar el bilingüismo de la sociedad vasca introduciendo más de una lengua vehicular. Sin duda consideramos que se deberá seguir de cerca qué tendencias adoptan las producciones futuras. También sería interesante ahondar en el empleo de diferentes dialectos y analizar la función que se atribuye en cada caso al empleo intencionado de un dialecto concreto y lo que representa.

Por otra parte, sería necesario un análisis pormenorizado de la subtitulación o del doblaje de diferentes largometrajes para conocer cómo se transmiten las diferentes identidades existentes en las obras originales y también para ver si se representa el multilingüismo del mismo modo que en los productos originales.

Como hemos observado, la difusión del cine en euskera puede variar dependiendo del género de cada producto y del ámbito geográfico en que se distribuya. Hemos visto que las películas de animación tienden a doblarse, los documentales a subtitularse y las películas de ficción se presentan en ambas modalidades en el caso del castellano, y utilizan la subtitulación en el caso de otras lenguas. Por otra parte, al referirnos a la difusión deberemos reparar en el espacio geográfico. La diglosia es más que visible en el País Vasco, diglosia tanto de la propia industria como de la distribución de las películas. Las versiones originales sin traducción raras veces se emiten en salas comerciales, y el espectador accede a ellas cuando llegan a las plataformas digitales, al DVD o a la televisión, es decir, su consumo se limita al ámbito doméstico, ya que los potenciales espectadores de la versión original tienen que acceder a la versión subtitulada o doblada en salas comerciales. Además, en las emisiones en salas comerciales, no siempre se ofrece la información necesaria para saber cuál es la copia que se emite en cada sala o, en su caso, el espectador no es consciente de que existen dos copias diferentes, por lo que puede ir al cine pensando que va a ver la película en versión original y acabe en una sesión doblada.

Por lo que se refiere a la distribución exterior, al tratarse de una cinematografía reducida y marginal dentro del mercado nacional e internacional, es imposible competir con las producciones más comerciales, por lo que las 
películas en euskera se estrenan en circuitos más modestos. Sería interesante que otras investigaciones pudieran ocuparse de realizar un estudio de recepción pormenorizado y analizar los datos por géneros.

Entre los retos presentes y futuros cabría mencionar los esfuerzos por aumentar el público, mejorar la calidad de las películas y ampliar el corpus, para lo cual es imprescindible que exista un sistema de financiación adecuado. Sería conveniente observar qué tipo de productos se comercializan en euskera y compararlos con la oferta disponible en otras lenguas. También habría que observar las implicaciones sociolingüísticas, pues el dominio lingüístico de los espectadores puede ser un factor determinante para atraerlos o alejarlos de las salas de cine. Por último, la falta de promoción también puede constituir un problema, ya que, a falta de suficiente presupuesto, se destina una inversión muy escasa a la difusión.

Para finalizar, sería recomendable reflexionar sobre un adecuado tratamiento lingüístico, tanto de las versiones originales como de las versiones traducidas, aunque cada género, y, de manera más particular, cada película, necesitará trabajar en sus propios criterios lingüísticos. Los cineastas deberían ser conscientes desde un principio de que sus productos tendrán diferentes versiones y que las copias finales en las diferentes lenguas tendrían que adecuarse a las necesidades de los diferentes espectadores. Ello contribuiría a una mayor concienciación sobre sus productos multilingües y a responder mejor a las necesidades lingüísticas del público.

Esta contribución es solo el primer estadio de un estudio que todavía requiere un análisis más profundo. El periodo productivo del que goza actualmente el cine en euskera puede ser un buen momento para observar lo que se ha realizado y reflexionar sobre su producción futura.

\section{Referencias bibliográficas}

ARAMENDI, Agurtzane. (2014) "Ze tamaina du euskarazko zinemagintzak?” Blogseitb. <http://www.blogseitb.net/euskara/2014/03/20/ ze-tamaina-du-euskarazko-zinemagintzak/>

BARAMBONES, Josu. (2011) "Una mirada telescópica al cine en euskera: versiones originales, dobladas y subtituladas." Hermeneus 13, pp. 25-59.

BARAMBONES, Josu. (2012) Lenguas minoritarias y traducción: la traducción audiovisual en euskera. Castelló: Servei de Publicacions de la Universitat Jaume I.

BARAMBONES, Josu; Raquel Merino \& Ibon Uribarri. (2012) "Audiovisual Translation in the Basque Country: The Case of Basque Television-Euskal Telebista (ETB)." Meta 57, pp. 408-422. 
BOPV, 23 de junio de 2016. ORDEN de 23 de junio de 2016, de la Consejera de Educación, Política Lingüistica y Cultura, por la que se regula y convoca el régimen de concesión de subvenciones durante el ejercicio 2016 a la creación cultural. Versión electrónica: <https://www.euskadi.eus/y22-bopv/es/bopv2/datos/ 2016/07/1603231a.pdf>

CorriUs, Montse \& Patrick Zabalbeascoa. (2011) "Language variation in source texts and their translations." Target 23:1, pp. 113-130.

GoÑI, Maialen. (2014) "Zein izan zen Donostiako Zinemaldian aurkeztu zuten euskarazko lehen filma?” En: Zinea.eus. <http://zinea.eus/2014/07/09/ba-aldakizu-donostiako-zinemaldian-aurkeztu-zuten-euskarazko-lehen-filma/>

GutiÉRreZ, Juan Miguel. (1994) "Euskal Zinea, Cine Vasco." RIEV. Revista Internacional de Estudios Vascos 2:XXXIX, pp. 277-295.

Junguitu, Maitane. (2016) "El camino de la coproducción en el largometraje de animación vasco." Con A de animación número extra 6, pp. 190-205.

LARRINAGA, Asier. (2010) "El inicio de una nueva era en la traducción audiovisual y el doblaje en euskera." En: Montero Domínguez, Xoán (ed.) 2010. A Tradución para a dobraxe en Galicia, País Vasco e Cataluña: experiencias investigadoras e profesionais. Vigo: Universidade de Vigo, pp. 95-112.

MANIAS MUÑOZ, Miren. (2013) "Euskarazko fikziozko zinemaren susperraldi hauskorra (2005-2012)." Ikusgaiak 8, pp. 85-108. Versión electrónica: <http:// www.euskomedia.org/PDFAnlt/ikusgaiak/08/08085108.pdf>

MANIAS MUÑOZ, Miren. (2015) Euskarazko zinemaren produkzioa eta finantziazioa (2005-2012): hamaika fikziozko film-luzeren azterketa ekonomikoa. Bilbao: UPV/EHU. Tesis doctoral inédita.

MANTEROLA, Elizabete. (2014) La literatura vasca traducida. Berna: Peter Lang.

MARTINEZ, Josu. (2015) Gure (zinemaren) Sor Lekua. Eukarazko lehen filmaren aurkikuntza, historia eta analisia. Bilbao: UPV/EHU.

MARTINEZ, Josu et al. (2015) "Zinegin Basque film festival: A non-existent audience revealed." Participations 12:1, pp. 725-738.

Mejuto, Gillen. (2011) Translation in the Basque Language Film Polysystem. Londres: Universidad de Roehampton. Trabajo Fin de Máster.

ROLDÁN LARRETA, Carlos. (1996) "Euskera y cine: una relación conflictiva." Fontes linguae vasconum: Studia et documenta, 28:71, pp. 163-176.

RoldÁn LARRETA, Carlos. (1999) El cine del País Vasco: de Ama Lur (1968) a Airbag (1997). San Sebastián: Eusko Ikaskuntza.

URKIXO, Joanes. (2014) "Firmas invitadas. Joanes Urkixo - Escribir 'Lasa y Zabala'." Bloguionistas. <https://bloguionistas.wordpress.com/2014/10/20/ lasa-y-zabala/>

ZABAlBEASCOA, Patrick \& Elena Voellmer. (2014) "Accounting for multilingual films in translation studies: Intratextual translation in dubbing." En: 
Abend-David, Dror (ed.) 2014. Media and translation: An interdisciplinary approach. Londres: Continuum, pp. 25-52.

ZABALONDO, Beatriz. (2010) "Dificultades de la traducción para el doblaje en euskera." En: Montero Domínguez, Xoán (ed.) 2010. A Tradución para a dobraxe en Galicia, País Vasco e Cataluña: experiencias investigadoras e profesionais. Vigo: Universidade de Vigo, pp. 173-184.

\section{NOTA BIOGRÁFICA / BIONOTE}

Elizabete Manterola Agirrezabalaga es profesora de Traducción e Interpretación en la Facultad de Letras de la Universidad del País Vasco UPV/ EHU. Defendió su tesis doctoral en 2012, en la que estudió la traducción de literatura vasca a otras lenguas. Su investigación se centra en la traducción en lenguas minoritarias, la literatura vasca y la traducción, la autotraducción, el heterolingüismo, así como la difusión y la traducción de cine vasco. Ha publicado el libro titulado La literatura vasca traducida (Peter Lang, 2014), así como varios artículos en revistas y volúmenes colectivos.

Elizabete Manterola Agirrezabalaga is lecturer of Translation and Interpreting at the University of the Basque Country UPV/EHU. She completed her PhD in 2012, which focused on the translation of Basque literature into foreign languages. Her research interests include translation within minority language contexts, Basque literature and translation, self-translation, heterolingualism, and the translation and diffusion of Basque cinema. She is the author of the books La literatura vasca traducida (Peter Lang, 2014) and many other papers published in journals and collective books. 


\section{Anexo I. Catálogo}

Este anexo recoge el catálogo de largometrajes en euskera desde 1956 hasta 2016. Las películas se presentan ordenadas por año de distribución:

\begin{tabular}{|c|c|c|c|c|}
\hline Título en euskera & $\begin{array}{l}\text { Título en } \\
\text { castellano }\end{array}$ & Director/a & Año & Género \\
\hline Gure Sor Lekua & -- & André Madré & 1956 & Documental \\
\hline Ama Lur & Tierra madre & $\begin{array}{l}\text { Nestor } \\
\text { Basterretxea } \\
\text { y Fernando } \\
\text { Larruquert }\end{array}$ & 1968 & Documental \\
\hline Axut & -- & Jose Mari Zabala & 1976 & Experimental \\
\hline Balantzatxoa & -- & $\begin{array}{l}\text { Juan Miguel } \\
\text { Gutiérrez Márquez }\end{array}$ & 1978 & $\begin{array}{l}\text { Ficción para } \\
\text { niños }\end{array}$ \\
\hline Sabino Arana & -- & $\begin{array}{l}\text { Pedro de la } \\
\text { Sota, Jose Julian } \\
\text { Bakedano }\end{array}$ & 1980 & Documental \\
\hline Erreporteroak & Los reporteros & Iñaki Aizpuru & 1984 & Ficción \\
\hline Kalabaza tripontzia & $\begin{array}{l}\text { La calabaza } \\
\text { mágica }\end{array}$ & $\begin{array}{l}\text { Juan Bautista } \\
\text { Berasategi }\end{array}$ & 1985 & Animación \\
\hline Kareletik & Por la borda & Anjel Lertxundi & 1987 & Ficción \\
\hline Lau haizetara & A los cuatro vientos & $\begin{array}{l}\text { Jose Antonio } \\
\text { Zorrilla }\end{array}$ & 1987 & Ficción \\
\hline Ander eta Yul & Ander $y$ Yul & Ane Díez & 1989 & Ficción \\
\hline Ke arteko egunak & Días de humo & Antxon Ezeiza & 1989 & Ficción \\
\hline $\begin{array}{l}\text { Ipar haizearen } \\
\text { erronka }\end{array}$ & $\begin{array}{l}\text { La leyenda del } \\
\text { viento norte }\end{array}$ & $\begin{array}{l}\text { Juan Bautista } \\
\text { Berasategi }\end{array}$ & 1991 & Animación \\
\hline Balearenak & Balleneros & $\begin{array}{l}\text { Juan Bautista } \\
\text { Berasategi }\end{array}$ & 1991 & Animación \\
\hline Offeko maitasuna & Amor en off & Koldo Izagirre & 1992 & Ficción \\
\hline Urte ilunak & Los años oscuros & Arantxa Lazcano & 1993 & Ficción \\
\hline $\begin{array}{l}\text { Ipar haizearen } \\
\text { itzulera }\end{array}$ & $\begin{array}{l}\text { El regreso del } \\
\text { viento norte }\end{array}$ & $\begin{array}{l}\text { Maite Ruiz de } \\
\text { Austri }\end{array}$ & 1994 & Animación \\
\hline $\begin{array}{l}\text { Ahmed. Alhambrako } \\
\text { printzea }\end{array}$ & $\begin{array}{l}\text { Ahmed, Principe de } \\
\text { la Alhambra }\end{array}$ & $\begin{array}{l}\text { Juan Bautista } \\
\text { Berasategi }\end{array}$ & 1998 & Animación \\
\hline Karramarro uhartea & La isla del cangrejo & $\begin{array}{l}\text { Joxean Muñoz y } \\
\text { Txabi Basterretxea }\end{array}$ & 2000 & Animación \\
\hline $\begin{array}{l}\text { Olentzero, } \\
\text { Gabonetako ipuina }\end{array}$ & $\begin{array}{l}\text { Olentzero. Un } \\
\text { cuento de Navidad }\end{array}$ & Juanjo Elordi & 2002 & Animación \\
\hline
\end{tabular}




\begin{tabular}{|c|c|c|c|c|}
\hline Betizu izar artean & $\begin{array}{l}\text { Betizu entre las } \\
\text { estrellas }\end{array}$ & Egoitz Rodriguez & 2003 & Animación \\
\hline Glup & -- & $\begin{array}{l}\text { Aitor Arregi y } \\
\text { Iñigo Berasategi }\end{array}$ & 2003 & Animación \\
\hline Supertramps & -- & $\begin{array}{l}\text { Jose Maria } \\
\text { Goenaga y Iñigo } \\
\text { Berasategi }\end{array}$ & 2004 & Animación \\
\hline $\begin{array}{l}\text { Unibertsolariak, } \\
\text { munduaren ertzaren } \\
\text { bila }\end{array}$ & $\begin{array}{l}\text { Los Balunis en la } \\
\text { aventura del fin del } \\
\text { mundo }\end{array}$ & Juanjo Elordi & 2004 & Animación \\
\hline Aupa Etxebeste! & -- & $\begin{array}{l}\text { Telmo Esnal y } \\
\text { Asier Altuna }\end{array}$ & 2005 & Ficción \\
\hline BT, Ispiluen Jauregian & -- & $\begin{array}{l}\text { Alberto J. } \\
\text { Gorritiberea }\end{array}$ & 2005 & Musical \\
\hline $\begin{array}{l}\text { Olentzero eta } \\
\text { subilaren lapurreta }\end{array}$ & $\begin{array}{l}\text { Olentzero y el } \\
\text { Tronco Mágico }\end{array}$ & Juanjo Elordi & 2005 & Animación \\
\hline $\begin{array}{l}\text { Txirri, Mirri eta } \\
\text { Txiribiton pelikula. } \\
\text { Pailazokeriak }\end{array}$ & & Imanol Zinkunegi & 2005 & Animación \\
\hline Zeru horiek & [Esos cielos] & Aizpea Goenaga & 2005 & Ficción \\
\hline Agian & -- & Arkaitz Basterra & 2006 & Documental \\
\hline $\begin{array}{l}\text { Kutxidazu bidea, } \\
\text { Ixabel }\end{array}$ & $\begin{array}{l}\text { Enséñame el } \\
\text { camino, Isabel }\end{array}$ & $\begin{array}{l}\text { Fernando Bernués, } \\
\text { Mireia Gabilondo }\end{array}$ & 2006 & Ficción \\
\hline Nömadak TX & -- & $\begin{array}{l}\text { Harkaitz Martínez } \\
\text { de San Vicente, } \\
\text { Igor Otxoa, Pablo } \\
\text { Iraburu y Raúl de } \\
\text { la Fuente }\end{array}$ & 2006 & Documental \\
\hline $\begin{array}{l}\text {... txoriak galduta } \\
\text { egozanian }\end{array}$ & $\begin{array}{l}\text {... cuando los } \\
\text { pájaros estaban } \\
\text { perdidos }\end{array}$ & $\begin{array}{l}\text { Jose Maria } \\
\text { González Sánchez }\end{array}$ & 2006 & Documental \\
\hline Kubo magikoa & El cubo mágico & Angel Izquierdo & 2006 & Animación \\
\hline $\begin{array}{l}\text { Betizu eta Xangaduko } \\
\text { misterioa }\end{array}$ & $\begin{array}{l}\text { Betizu y el misterio } \\
\text { de Xangadú }\end{array}$ & Egoitz Rodriguez & 2006 & Animación \\
\hline Cristobal Molon & -- & $\begin{array}{l}\text { Iñigo Berasategi y } \\
\text { Aitor Arregi }\end{array}$ & 2006 & Animación \\
\hline $\begin{array}{l}\text { Betizu eta urrezko } \\
\text { zintzarria }\end{array}$ & -- & Egoitz Rodriguez & 2007 & Animación \\
\hline Eutsi! & -- & $\begin{array}{l}\text { Alberto J. } \\
\text { Gorritiberea }\end{array}$ & 2007 & Ficción \\
\hline $\begin{array}{l}\text { Olentzero eta } \\
\text { Amilaren sekretua }\end{array}$ & El secreto de Amila & Gorka Vázquez & 2007 & Animación \\
\hline
\end{tabular}




\begin{tabular}{|c|c|c|c|c|}
\hline Ander & -- & Roberto Castón & 2009 & Ficción \\
\hline Go!azen & -- & $\begin{array}{l}\text { Jabi Elortegi y } \\
\text { Aitor Aranguren }\end{array}$ & 2008 & Musical \\
\hline Bidaia intimoak & -- & Jon Maia & 2009 & Documental \\
\hline Zorion perfektua & Felicidad perfecta & Jabier Elortegi & 2009 & Ficción \\
\hline $\begin{array}{l}\text { Munduaren bira, } \\
\text { doan! }\end{array}$ & $\begin{array}{l}\text { La vuelta al } \\
\text { mundo, igratis! }\end{array}$ & $\begin{array}{l}\text { Juanjo Elordi y } \\
\text { Asisko Urmeneta }\end{array}$ & 2008 & Animación \\
\hline Animal Channel & -- & $\begin{array}{l}\text { Maite Ruiz de } \\
\text { Austri }\end{array}$ & 2008 & Animación \\
\hline $\begin{array}{l}\text { Barriola, San } \\
\text { Adriango azeria }\end{array}$ & El zorro ladrón & $\begin{array}{l}\text { Juan Bautista } \\
\text { Berasategi }\end{array}$ & 2008 & Animación \\
\hline $\begin{array}{l}\text { Olentzero eta oparien } \\
\text { ordua }\end{array}$ & $\begin{array}{l}\text { Olentzero y la hora } \\
\text { de los regalos }\end{array}$ & Gorka Sesma & 2008 & Animación \\
\hline Sukalde kontuak & Secretos de cocina & Aizpea Goenaga & 2009 & Ficción \\
\hline 80 egunean & En 80 días & $\begin{array}{l}\text { Jon Garaño y Jose } \\
\text { Mari Goenaga }\end{array}$ & 2010 & Ficción \\
\hline Aita & -- & Jose Maria de Orbe & 2010 & Ficción \\
\hline Amerikanuak & -- & $\begin{array}{l}\text { Ignacio Reig y } \\
\text { Gorka Bilbao }\end{array}$ & 2010 & Documental \\
\hline Izarren argia & $\begin{array}{l}\text { Estrellas que } \\
\text { alcanzar }\end{array}$ & Mikel Rueda & 2010 & Ficción \\
\hline Perurena & -- & Jon Garaño & 2010 & Documental \\
\hline Sagarren denbora & $\begin{array}{l}\text { El tiempo de las } \\
\text { manzanas }\end{array}$ & $\begin{array}{l}\text { Josu Martínez y } \\
\text { Txaber Larreategi }\end{array}$ & 2010 & Documental \\
\hline Ttaup, ttaup! & -- & Eneko Dorronsoro & 2010 & Documental \\
\hline Zigortzaileak & Los castigadores & $\begin{array}{l}\text { Arantza Ibarra y } \\
\text { Alfonso Arandia }\end{array}$ & 2010 & Ficción \\
\hline Mystical & -- & Angel Alonso & 2010 & Animación \\
\hline $\begin{array}{l}\text { Midas erregearen } \\
\text { altxorra }\end{array}$ & $\begin{array}{l}\text { El tesoro del rey } \\
\text { Midas }\end{array}$ & $\begin{array}{l}\text { Maite Ruiz de } \\
\text { Austri }\end{array}$ & 2010 & Animación \\
\hline Arriya & & $\begin{array}{l}\text { Alberto J. } \\
\text { Gorritiberea }\end{array}$ & 2011 & Ficción \\
\hline Azken bidaia & El último viaje & $\begin{array}{l}\text { Enara Goikoetxea } \\
\text { y Iurre Telleria }\end{array}$ & 2011 & Documental \\
\hline Bertsolari & -- & Asier Altuna & 2011 & Documental \\
\hline Bi anai & Dos hermanos & Imanol Rayo & 2011 & Ficción \\
\hline Gartxot & -- & $\begin{array}{l}\text { Asisko Urmeneta y } \\
\text { Juanjo Elordi }\end{array}$ & 2011 & Animación \\
\hline Gazta zati bat & Un trozo de queso & Jon Maia & 2011 & Documental \\
\hline
\end{tabular}




\begin{tabular}{|c|c|c|c|c|}
\hline Mugaldekoak & $\begin{array}{l}\text { Mugaldekoak. } \\
\text { Operación Comète }\end{array}$ & $\begin{array}{l}\text { Fernando Bernués } \\
\text { y Mireia Gabilondo }\end{array}$ & 2011 & Ficción \\
\hline Urte berri on, amona & -- & Telmo Esnal & 2011 & Ficción \\
\hline $\begin{array}{l}\text { Olentzero eta } \\
\text { Iratxoen Jauntxoa }\end{array}$ & -- & Gorka Vázquez & 2011 & Animación \\
\hline Aita, zonbia naiz & Papá, soy un zombi & $\begin{array}{l}\text { Ricardo Ramón y } \\
\text { Joan Espinach }\end{array}$ & 2011 & Animación \\
\hline The Wish Fish & -- & $\begin{array}{l}\text { Gorka Vázquez e } \\
\text { Iván Oneka }\end{array}$ & 2011 & Animación \\
\hline $\begin{array}{l}\text { Barrura begiratzeko } \\
\text { leihoak }\end{array}$ & Ventanas al interior & $\begin{array}{l}\text { Eneko Olasagasti, } \\
\text { Josu Martinez, } \\
\text { Mireia Gabilondo, } \\
\text { Txaber Larreategi y } \\
\text { Enara Goikoetxea }\end{array}$ & 2012 & Documental \\
\hline Baztan & -- & Iñaki Elizalde & 2012 & \\
\hline Bypass & -- & $\begin{array}{l}\text { Patxo Telleria y } \\
\text { Aitor Mazo }\end{array}$ & 2012 & Ficción \\
\hline Dragoi ehiztaria & $\begin{array}{l}\text { El cazador de } \\
\text { dragones }\end{array}$ & Patxi Barko & 2012 & Ficción \\
\hline Emak Bakia Baita & -- & Oskar Alegria & 2012 & Documental \\
\hline $\begin{array}{l}\text { Galerna, ekaitz } \\
\text { ezezaguna }\end{array}$ & $\begin{array}{l}\text { Galerna. La } \\
\text { tormenta } \\
\text { desconocida }\end{array}$ & Jabier Elortegi & 2012 & Documental \\
\hline Haritzaren bihotza & $\begin{array}{l}\text { El corazón del } \\
\text { roble }\end{array}$ & $\begin{array}{l}\text { Angel Izquierdo } \\
\text { y Ricardo Ramón } \\
\text { González }\end{array}$ & 2012 & Animación \\
\hline Mur-mur & Murmullos & Juanmi Gutiérrez & 2012 & Documental \\
\hline Tormesko itsumutila & $\begin{array}{l}\text { El lazarillo de } \\
\text { Tormes }\end{array}$ & Juanba Berasategi & 2012 & Animación \\
\hline Xora & -- & Peio Cachenaut & 2012 & Ficción \\
\hline Zuloak & -- & Fermin Muguruza & 2012 & Documental \\
\hline Alaba zintzoa & & $\begin{array}{l}\text { Javier Rebollo y } \\
\text { Alvar Gordejuela }\end{array}$ & 2013 & Ficción \\
\hline Amaren eskuak & $\begin{array}{l}\text { Las manos de mi } \\
\text { madre }\end{array}$ & Mireia Gabilondo & 2013 & Ficción \\
\hline Asier eta biok & Asier y yo & $\begin{array}{l}\text { Aitor Merino y } \\
\text { Amaia Merino }\end{array}$ & 2013 & Documental \\
\hline $\begin{array}{l}\text { Lucius Dumben } \\
\text { berebiziko bidaia }\end{array}$ & $\begin{array}{l}\text { El extraordinario } \\
\text { viaje de Lucius } \\
\text { Dumb }\end{array}$ & $\begin{array}{l}\text { Maite Ruiz de } \\
\text { Austri }\end{array}$ & 2013 & Animación \\
\hline Umezurtzak & Los huérfanos & Ernesto del Río & 2013 & Ficción \\
\hline
\end{tabular}




\begin{tabular}{|c|c|c|c|c|}
\hline $\begin{array}{l}\text { Behobia-Donostia: } \\
20 \text { kilometro, mila } \\
\text { istorio }\end{array}$ & $\begin{array}{l}\text { Behobia-Donostia. } \\
20 \text { kilómetros, mil } \\
\text { historias }\end{array}$ & Xuban Intxausti & 2014 & Documental \\
\hline Bingen & & Ander Odriozola & 2014 & Ficción \\
\hline $\begin{array}{l}\text { Dixie eta matxinada } \\
\text { zonbia }\end{array}$ & $\begin{array}{l}\text { Dixie y la } \\
\text { revolución zombi }\end{array}$ & $\begin{array}{l}\text { Ricardo Ramón y } \\
\text { Beñat Beitia }\end{array}$ & 2014 & Animación \\
\hline Euskara munduan & -- & Iñigo Asensio & 2014 & Documental \\
\hline Goazen gudari danok & -- & Iban González & 2014 & Documental \\
\hline $\begin{array}{l}\text { Ikastola: mende oso } \\
\text { bat euskarari }\end{array}$ & -- & $\begin{array}{l}\text { Kike Amonarriz, } \\
\text { Lander Garro y } \\
\text { Xabier Zapirain }\end{array}$ & 2016 & Documental \\
\hline Lasa eta Zabala & Lasa y Zabala & Pablo Malo & 2014 & Ficción \\
\hline Loreak & Flores & $\begin{array}{l}\text { Jon Garaño y Jose } \\
\text { Mari Goenaga }\end{array}$ & 2014 & Ficción \\
\hline $\begin{array}{l}\text { Xalbador, izena eta } \\
\text { izana }\end{array}$ & -- & Eneko Dorronsoro & 2014 & Documental \\
\hline Zohardia & -- & $\begin{array}{l}\text { Lander Iruin y } \\
\text { Markel Andia }\end{array}$ & 2014 & Documental \\
\hline Amama & -- & Asier Altuna & 2015 & Ficción \\
\hline $\begin{array}{l}\text { Gaur irekiko ditu } \\
\text { ateak }\end{array}$ & $\begin{array}{l}\text { Hoy abrirá sus } \\
\text { puertas }\end{array}$ & Eriz Zapirain & 2015 & Documental \\
\hline Gernika batailoia & Batallón Gernika & Iban Gonzalez & 2015 & Documental \\
\hline $\begin{array}{l}\text { Gure Sor Lekuaren } \\
\text { bila }\end{array}$ & $\begin{array}{l}\text { En busca de Gure } \\
\text { Sor Lekua }\end{array}$ & Josu Martinez & 2015 & Documental \\
\hline Pikadero & -- & Ben Sharrock & 2015 & Ficción \\
\hline Txarriboda & La matanza & $\begin{array}{l}\text { Javier Rebollo y } \\
\text { Alvar Gordejuela }\end{array}$ & 2015 & Ficción \\
\hline Yoko eta lagunak & Yoko y sus amigos & Juanjo Elordi & 2015 & Animación \\
\hline Jai Alai Blues & -- & Gorka Bilbao & 2015 & Documental \\
\hline Oroimena bizigune & Habitar la memoria & Alaitz Arenzana & 2015 & Documental \\
\hline $\begin{array}{l}\text { Sabino Aranaren } \\
\text { begiak }\end{array}$ & -- & Joseba Gorordo & 2015 & Documental \\
\hline Sagardoa bidegile & Historias de sidra & Bego Zubia & 2015 & Documental \\
\hline Gutik zura & -- & $\begin{array}{l}\text { Jon Maia y Mari } \\
\text { Jose Barriola }\end{array}$ & 2016 & Documental \\
\hline Igelak & Ranas & Patxo Telleria & 2016 & Ficción \\
\hline $\begin{array}{l}\text { Igorre, } 40 \text { urte } \\
\text { ziklokrossean }\end{array}$ & $\begin{array}{l}\text { Igorre, } 40 \text { años en } \\
\text { el ciclocross }\end{array}$ & Xabier Zabala & 2016 & Documental \\
\hline
\end{tabular}




\begin{tabular}{|c|c|c|c|c|}
\hline Kalebegiak & -- & $\begin{array}{l}\text { Obra colectiva } \\
\text { de } 12 \text { directores: } \\
\text { Koldo Almandoz, } \\
\text { Asier Altuna, Luiso } \\
\text { Berdejo, Daniel } \\
\text { Calparsoro, Iñaki } \\
\text { Camacho, Borja } \\
\text { Cobeaga, María } \\
\text { Elorza, Telmo } \\
\text { Esnal, Maider } \\
\text { Fernandez Iriarte, } \\
\text { Isabel Herguera, } \\
\text { Ekain Irigoien, } \\
\text { Julio Medem, } \\
\text { Izibene Oñederra, } \\
\text { Gracia Querejeta, } \\
\text { Imanol Uribe }\end{array}$ & 2016 & Ficción \\
\hline Neskatoak & Criadas & Jon Abril & 2016 & Documental \\
\hline $\begin{array}{l}\text { Pixi Post eta opari } \\
\text { emaileak }\end{array}$ & $\begin{array}{l}\text { Pixi Post y los } \\
\text { genios de Navidad }\end{array}$ & Gorka Sesma & 2016 & Animación \\
\hline Sipo Phantasma & -- & Koldo Almandoz & 2016 & Experimental \\
\hline
\end{tabular}

\section{Anexo II. Filmografía citada no incluida en el catálogo}

Este anexo recoge las referencias a las películas citadas en los apartados 2 y 3 que han quedado fuera del catálogo. Se trata de películas que no cumplen con los criterios establecidos. Se presentan en orden cronológico:

\begin{tabular}{|l|l|l|c|l|}
\hline \multicolumn{1}{|c|}{ Título en euskera } & $\begin{array}{c}\text { Título en } \\
\text { castellano }\end{array}$ & \multicolumn{1}{c|}{ Director/a } & Año & \multicolumn{1}{c|}{ Género } \\
\hline Au Pays des Basques & & $\begin{array}{l}\text { Jean Faugeres, } \\
\text { Maurice } \\
\text { Champreux }\end{array}$ & 1930 & Documental \\
\hline Ereagatik Matxitxakora & & Gotzon Elorza & 1959 & Documental \\
\hline Aberria/Erria & & Gotzon Elorza & 1961 & Documental \\
\hline Elburua: Gernika & & Gotzon Elorza & 1962 & Documental \\
\hline Avignon & & Gotzon Elorza & 1964 & Documental \\
\hline Ikuska & & Antton Ezeiza & $1979-$ & $\begin{array}{l}\text { Serie } \\
\text { documental }\end{array}$ \\
\hline Euskara eta kirola & -- & $\begin{array}{l}\text { Antton Ezeiza y } \\
\text { Koldo Izagirre }\end{array}$ & 1980 & $\begin{array}{l}\text { Serie } \\
\text { documental }\end{array}$ \\
\hline Ehun metro & Cien metros & Alfonso Ungría & 1985 & Ficción \\
\hline
\end{tabular}




\begin{tabular}{|c|c|c|c|c|}
\hline $\begin{array}{l}\text { Hamaseigarrenean, } \\
\text { aidanez }\end{array}$ & $\begin{array}{l}\text { Ocurrió a la } \\
\text { decimosexta }\end{array}$ & Anjel Lertxundi & 1985 & Ficción \\
\hline Zergatik panpox? & $\begin{array}{l}\text { ¿Por qué } \\
\text { Panpox? }\end{array}$ & $\begin{array}{l}\text { Xabier } \\
\text { Elorriaga }\end{array}$ & 1985 & Ficción \\
\hline Oraingoz izen gabe & & $\begin{array}{l}\text { Jose Luis } \\
\text { Bakedano }\end{array}$ & 1986 & Ficción \\
\hline 27 ordu & 27 horas & $\begin{array}{l}\text { Montxo } \\
\text { Armendáriz }\end{array}$ & 1986 & Ficción \\
\hline Maité & Maité & $\begin{array}{l}\text { Eneko } \\
\text { Olasagasti y } \\
\text { Carlos Zabala }\end{array}$ & 1994 & Ficción \\
\hline Obaba & Obaba & $\begin{array}{l}\text { Montxo } \\
\text { Armendáriz }\end{array}$ & 2005 & Ficción \\
\hline Zortzi euskal abizen & $\begin{array}{l}\text { Ocho apellidos } \\
\text { vascos }\end{array}$ & $\begin{array}{l}\text { Emilio } \\
\text { Martínez-Lázaro }\end{array}$ & 2014 & Ficción \\
\hline
\end{tabular}

Au Pays des Basques queda fuera del catálogo porque está rodada en francés y el euskera no constituye la Ll de la película. Sucede lo mismo en el caso de Maité, Obaba, 27 horas y Ocho apellidos vascos, en los cuales la presencia del euskara es testimonial.

Por otra parte, los documentales de Gotzon Elorza y las 4 películas de ficción producidas en los 80 no se han tenido en cuenta en la catalogación por tratarse de mediometrajes y no llegar a la longitud mínima establecida. La serie documental Ikuska está formado por 20 capítulos de unos 9-14 minutos de duración, por lo que tampoco se han incluido en el catálogo. La serie documental Euskara eta kirola, por su parte, está formada por tres cortometrajes sobre el deporte y el euskera que tratan sobre el remo, el fútbol y el montañismo. 